\title{
Effect of Rhodamine B Dye on the Thermal, Mechanical, Dielectric, Laser Damage Threshold and Optical Properties of L-Alanine Thiourea (LATU) Single Crystals
}

\author{
R. Kannan \\ Department of Physics \\ Presidency College, \\ Chennai-600005, \\ Tamilnadu, India
}

\author{
D. Jayaraman \\ Department of Physics \\ Presidency College, \\ Chennai-600005, \\ Tamilnadu, India
}

\author{
S. Aravindhan \\ Department of Physics \\ Presidency College, \\ Chennai-600005, \\ Tamilnadu, India
}

\begin{abstract}
Effect of Rhodamine B dye on the growth and properties of L-Alanine Thiourea Bulk single crystals has been reported. The cell parameters and crystallinity of pure and dye admixtured LATU crystals were confirmed by single crystal, powder X-ray diffraction and high resolution X-ray diffraction analyses. The functional groups present in the crystals were confirmed by FTIR analysis. The UV-vis-NIR transmission studies show the optical transparency in the entire visible region of Rhodamine B dye admixtured LATU crystal. The laser damage threshold value significantly enhanced for dye admixtured crystal in comparison with pure LATU crystal. The crystals were further subjected to other important characterizations such as dielectric measurement, micro hardness, thermal and NLO studies. The relative SHG efficiency of Rhodamine B dye admixtured LATU crystal was found to be 1.46 times higher than that of pure LATU crystal.
\end{abstract}

Keywords: slow evaporation technique, powder X-ray diffraction, dielectric properties, nonlinear optical study.

\section{INTRODUCTION}

The recent advances in science and technology have brought a great demand of various crystals with numerous applications. A field of multidisciplinary nature in science and technology has been emerged, known as crystal growth, which deals with the crystal growth methods, crystals characterizations and crystal growth theories. Nonlinear optical (NLO) crystals are a key material for the development of laser science and technology because there is almost only this kind of materials that have functions to change frequency of laser beam and modulate it in amplitude and phase. It may be said that lasers could not be used so widely in modern science and technology as they have been today, without NLO crystals. Development of NLO crystals with better linear optical (LO) and NLO properties, wider spectral transmission and phase-matching range in particular is obviously essential for further widening the application field of lasers. That is why many scientists working in the field today are still putting in great effort to search for new NLO crystals, even more than four decades after the invention of the laser. Among organic crystals for nonlinear optics (NLO) applications, amino acids display specific features of interest [1], such as molecular chirality which secures acentric crystallographic structures, absence of strongly conjugated bonds, leading to wide transparency ranges in the visible and UV spectral regions and zwitterionic nature of the molecule, which favours crystal hardness. Further to that, amino acids can be used as chiral auxiliaries for nitro-aromatics and other donor-acceptor molecules with large hyperpolarizability [2]. The growth of large single crystals of amino acids has been little investigated so far, even as regards the simplest acentric member of the family, L-Alanine $\left(\mathrm{CH}_{3} \mathrm{CHNH}_{2} \mathrm{COOH}\right)$. L-Alanine was first crystallized by BERNAL and later by SIMPSON et al. and DESTRO et al., who refined the structure $(\mathrm{a}=6.032 \AA, \mathrm{b}=12.343 \AA$, $\mathrm{c}=5.784 \AA ; \alpha=\beta=\gamma=90^{\circ}$ ) and assigned it the $\mathrm{P} 2{ }_{1} 2_{1} 2_{1}$ space group [3-5]. In both cases, very small crystals were grown, unsuitable for optical investigations. In the recent years, complex of thiourea NLO crystals have attracted among the researchers [6] due to its flexibility in synthesis of a new complex. Thiourea ligand has both $\mathrm{S}$ and $\mathrm{N}$ donors; it can be coordinated either through $\mathrm{S}$ or $\mathrm{N}$ with few amino acid and forms a stable organic complex. Thiourea is an organic matrix modifier due to its large dipole moment and its ability to form hydrogen bonds [7]. A Thiourea crystal finds widespread use as frequency doublers in laser applications and was studied in great detail. Improvement in the quality of the Thiourea crystals and the performance of this crystal-based device can be realized with suitable dopants. To analyse the influence of dye based dopant on the centro symmetric Thiourea molecule, when combined with amino acids yields non-centrosymmetric complexes, which possess in general good nonlinear optical properties [8]. Some of the nonlinear crystals of the amino acid complexes of Thiourea reported are glycine Thiourea [9], and L-Histidine Thiourea [10]. Among these the second harmonic generation efficiency (SHG) of glycine Thiourea crystal was 0.5 times that of KDP and the SHG efficiency of L-Histidine Thiourea crystal 4.1 times that of KDP. Many researchers have worked on dye admixtured potassium dihydrogen phosphate and potassium acid phthalate nonlinear optical crystals in order to improve their nonlinear response $[11,12]$. Dyeing of crystals is a practice that was developed particularly for quantum optical applications because of the very significant increase in surface area achieved in growing crystals. Rhodamine is a family of related chemical compounds, fluorone dyes. Rhodamine dyes are used extensively in biotechnology applications such as fluorescence microscopy, flow cytometry, fluorescence correlation spectroscopy and Enzyme-Linked Immunosorbent Assay (ELISA). Rhodamine dyes are generally toxic, and are soluble in water, methanol and ethanol. Examples are Rhodamine 6G and Rhodamine B. Rhodamine B dye is used as laser gain medium. It is often used as a tracer dye within water to determine the rate and direction of flow and transport. Rhodamine B is tunable around $610 \mathrm{~nm}$ when used as a laser dye. In the present work, a comparative study on the growth, structural, UV-vis-NIR transmission, thermal, dielectric, mechanical, non-linear optical and laser damage threshold studies of pure and Rhodamine B dye admixtured LATU crystals have been reported. 


\section{EXPERIMENTAL PROCEDURE}

L-Alanine Thiourea (LATU) was synthesized by dissolving high purity Thiourea and L-Alanine in the equimolar ratio in aqueous medium. Thiourea was first dissolved in Millipore water and then L-Alanine was added with continuous stirring for about 2 hours using a magnetic stirrer at $50{ }^{\circ} \mathrm{C}$. The product was obtained as per the following reaction.

$$
\begin{gathered}
\mathrm{H}_{2} \mathrm{~N}-\mathrm{CS}_{-} \mathrm{NH}_{2}+\mathrm{CH}_{3} \mathrm{CHNH}_{2} \mathrm{COOH} \rightarrow \mathrm{H}_{2} \mathrm{~N}-\mathrm{CS}_{\text {(Thiourea }}+\mathrm{NH}_{3}{ }^{-} \mathrm{CH}_{3} \mathrm{CHNH}_{2} \mathrm{COO}^{+} \\
\text {L-Alanine }
\end{gathered}
$$

The impurity content of L-Alanine Thiourea (LATU) was minimized by the process of recrystallization. The $\mathrm{pH}$ value of the solution was about 7.24. The $\mathrm{pH}$ value was adjusted to 3.5 by adding few drops concentrated hydrochloric acid [14]. Then it was filtered using Whatmann filter paper and the filtered solution was kept in a borosil beaker covered with an aluminium foil and the solvent was allowed to evaporate at room temperature. As a result of slow evaporation, after 30 days, colourless and transparent LATU crystal with dimensions of $12 \times 3 \times 3 \mathrm{~mm}^{3}$ was obtained. The same experimental procedure was adopted for the synthesis of Rhodamine B dye ( $2 \mathrm{~mol} \%$ ) admixtured LATU salt. The seed crystal with perfect shape and free from macro defects was used for the growth of dye admixtured LATU crystal by slow evaporation method. The photographs of LATU and Rhodamine B dye admixtured LATU (RBLATU) crystals are shown in Figure 1 and Figure 2.

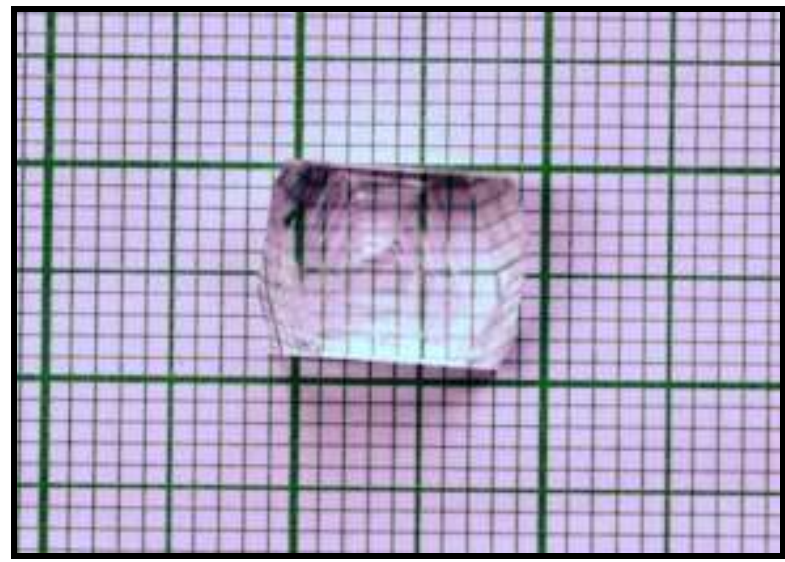

Figure 1. Grown LATU crystal

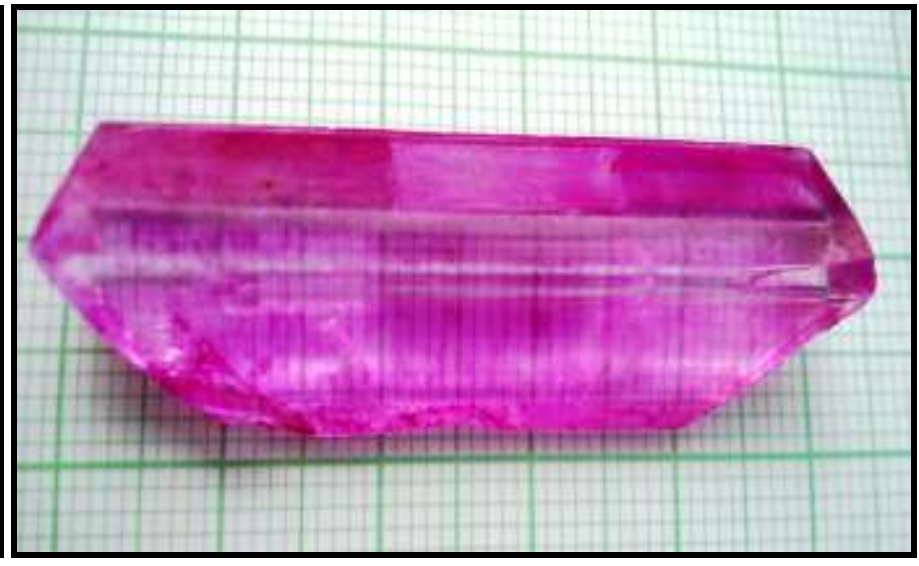

Figure 2. Grown RBLATU crystal

\section{RESULT AND DISCUSSION}

\subsection{Single crystal XRD analysis}

The single crystal XRD analysis of LATU and Rhodamine B dye admixtured LATU (RBLATU) crystals were carried out using MESSRS ENRAF NONIUS CAD4-F, single X-ray diffractometer with $\operatorname{MoK} \alpha(\lambda=0.71073 \AA)$ radiation. The lattice parameters of LATU and RBLATU crystals obtained from single crystal XRD analysis are presented in Table 1 . The single crystal XRD study reveals that the presence of dopant has not altered the basic structure of the LATU crystal. The lattice parameter values of Rhodamine B dye admixtured crystal may be attributed to the lattice strain in the grown crystals due to the incorporation of the dye dopant.

\begin{tabular}{|c|c|c|c|c|c|c|}
\hline S. No. & $\begin{array}{c}\text { Crystal } \\
\text { name }\end{array}$ & $\begin{array}{c}\text { Axial lengths } \\
\text { of unit cell } \\
\text { (a, b and c) }\end{array}$ & $\begin{array}{c}\text { Inter axial } \\
\text { angles } \\
(\alpha, \beta \text { and } \gamma)\end{array}$ & Volume & Crystal system & $\begin{array}{l}\text { Space } \\
\text { group }\end{array}$ \\
\hline 01. & LATU & $\begin{array}{l}\mathrm{a}=9.6312 \AA \\
\mathrm{b}=5.6136 \AA \\
\mathrm{c}=9.4142 \AA\end{array}$ & $\begin{array}{c}\alpha=\gamma=90^{\circ} \\
\beta=109.48^{\circ}\end{array}$ & $508.98 \AA^{3}$ & Monoclinic & $\mathrm{P} 2_{1}$ \\
\hline 02. & RBLATU & $\begin{array}{l}\mathrm{a}=9.6111 \AA \\
\mathrm{b}=5.6351 \AA \\
\mathrm{c}=9.4311 \AA\end{array}$ & $\begin{array}{c}\alpha=\gamma=90^{\circ} \\
\beta=109.48^{\circ}\end{array}$ & $510.78 \AA^{3}$ & Monoclinic & $\mathrm{P} 2_{1}$ \\
\hline
\end{tabular}

Table 1. Comparison of lattice parameters of LATU and RBLATU.

\subsection{Powder XRD Analysis}

The grown crystals of LATU and RBLATU were crushed into fine powder and powder X-ray diffraction analysis has been carried out using Rich Seifert X-ray diffractometer. 
Table 2. Miller indices, $d$-spacing and 20-values of L-Alanine Thiourea (LATU) single crystal determined from powder XRD analysis using RexCell software.

\begin{tabular}{|c|c|c|c|c|c|c|c|}
\hline S. No. & $\mathbf{h}$ & $\mathbf{k}$ & $\mathbf{l}$ & $\begin{array}{c}\mathbf{d}(\mathbf{o b s}) \\
\left(\mathbf{A}^{\circ}\right)\end{array}$ & $\begin{array}{c}\mathbf{d}(\mathbf{c a l c}) \\
\left(\mathbf{A}^{\circ}\right)\end{array}$ & $\begin{array}{c}\mathbf{2 \theta}(\mathbf{o b s}) \\
(\mathbf{d e g})\end{array}$ & $\begin{array}{c}\mathbf{2 \theta} \text { (calc) } \\
(\mathbf{d e g})\end{array}$ \\
\hline 1 & 2 & 0 & -1 & 4.59282 & 4.59479 & 19.303 & 19.294 \\
\hline 2 & 1 & 0 & -2 & 4.28883 & 4.28477 & 20.685 & 20.705 \\
\hline 3 & 1 & 1 & 1 & 3.81913 & 3.81395 & 23.263 & 23.295 \\
\hline 4 & 2 & 1 & 0 & 3.48218 & 3.48090 & 25.550 & 25.560 \\
\hline 5 & 3 & 0 & -1 & 3.13881 & 3.13725 & 28.401 & 28.415 \\
\hline 6 & 2 & 1 & -2 & 3.07372 & 3.07392 & 29.015 & 29.014 \\
\hline 7 & 2 & 1 & 1 & 2.93698 & 2.93525 & 30.398 & 30.417 \\
\hline 8 & 1 & 1 & 2 & 2.84657 & 2.84937 & 31.388 & 31.357 \\
\hline 9 & 3 & 1 & -1 & 2.73649 & 2.73839 & 32.685 & 32.662 \\
\hline 10 & 3 & 0 & 1 & 2.52323 & 2.52358 & 35.536 & 35.531 \\
\hline 11 & 1 & 2 & 1 & 2.46934 & 2.46928 & 36.338 & 36.339 \\
\hline 12 & 0 & 2 & 2 & 2.31055 & 2.31088 & 38.933 & 38.927 \\
\hline
\end{tabular}

The $\mathrm{X}$-axis of graph is $2 \theta$. The $\mathrm{Y}$-axis gives the intensity in arbitrary units. The samples were subjected to intense $\mathrm{X}$-ray of wavelength $1.5406 \AA(\mathrm{CuK} \alpha)$ at a scan speed of $1 \%$ minute to obtain lattice parameters. The Miller indices (hkl), d-spacing and diffraction angle

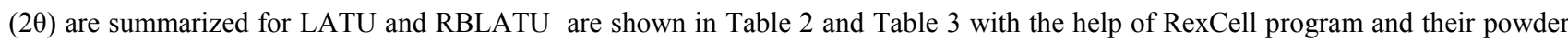
diffractograms are shown in Figure 3 \& Figure 4.

Table 3. Miller indices, d-spacing and 20-values of Rhodamine B dye admixtured LATU (RBLATU) single crystal determined from powder XRD analysis using RexCell software.

\begin{tabular}{|c|c|c|c|c|c|c|c|}
\hline S. No. & $\mathbf{h}$ & $\mathbf{k}$ & $\mathbf{l}$ & $\begin{array}{c}\mathbf{d}(\mathbf{o b s}) \\
\left(\mathbf{A}^{\circ}\right)\end{array}$ & $\begin{array}{c}\mathbf{d}(\mathbf{c a l c}) \\
\left(\mathbf{A}^{\circ}\right)\end{array}$ & $\begin{array}{c}\mathbf{2 \theta}(\mathbf{o b s}) \\
(\mathbf{d e g})\end{array}$ & $\begin{array}{c}\mathbf{2 \theta}(\mathbf{c a l c}) \\
(\mathbf{d e g})\end{array}$ \\
\hline 1 & 1 & 0 & 0 & 4.58479 & 4.58331 & 19.337 & 19.343 \\
\hline 2 & 0 & 1 & 0 & 4.43740 & 4.44123 & 19.986 & 19.968 \\
\hline 3 & 0 & 0 & 2 & 4.27836 & 4.28026 & 20.737 & 20.727 \\
\hline 4 & 0 & 1 & -2 & 3.81086 & 3.81282 & 23.314 & 23.302 \\
\hline 5 & 0 & 1 & 1 & 3.48218 & 3.47963 & 25.550 & 25.569 \\
\hline 6 & 2 & 0 & -3 & 3.13881 & 3.13886 & 28.401 & 28.401 \\
\hline 7 & 1 & -1 & -2 & 3.07372 & 3.07378 & 29.015 & 29.015 \\
\hline 8 & 1 & -1 & 1 & 2.93698 & 2.93576 & 30.398 & 30.411 \\
\hline 9 & 2 & 1 & -3 & 2.84657 & 2.84696 & 31.388 & 31.384 \\
\hline 10 & 2 & 0 & -1 & 2.73649 & 2.73706 & 32.685 & 32.678 \\
\hline 11 & 1 & -1 & -3 & 2.52323 & 2.52354 & 35.536 & 35.532 \\
\hline 12 & 2 & 1 & -5 & 2.46934 & 2.46885 & 36.338 & 36.346 \\
\hline 13 & 1 & 2 & -2 & 2.31055 & 2.31040 & 38.933 & 38.935 \\
\hline
\end{tabular}

From the X-ray powder diffraction data, the lattice parameters for RBLATU were found to be $a=9.6201 \AA$, $b=5.6401 \AA$ and $\mathrm{c}=9.4249 \AA$. This is in close agreement with the values obtained from single crystal X-ray diffraction analysis for RBLATU. The change in intensity of peaks as well as addition in number of peaks for RBLATU in the powder X-ray diffraction pattern reveal that the dye doped crystal is slightly distorted compared to the pure LATU. This may be attributed to strains on the lattice by the absorption or substitution of Rhodamine B dye in LATU crystal. 


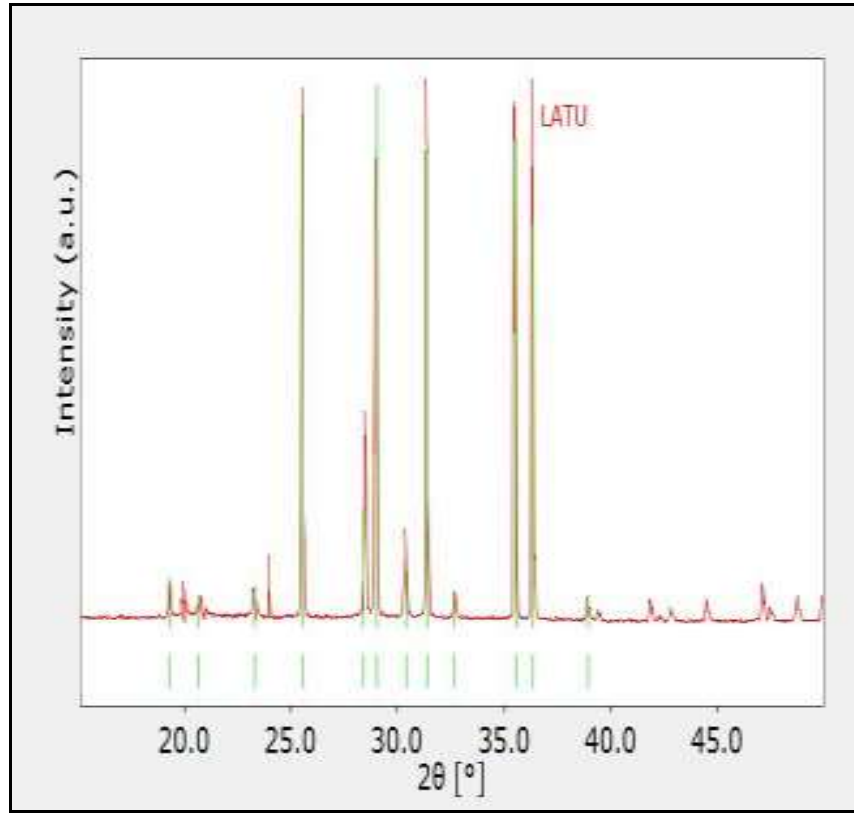

Figure 3. PWXRD spectrum of LATU crystal

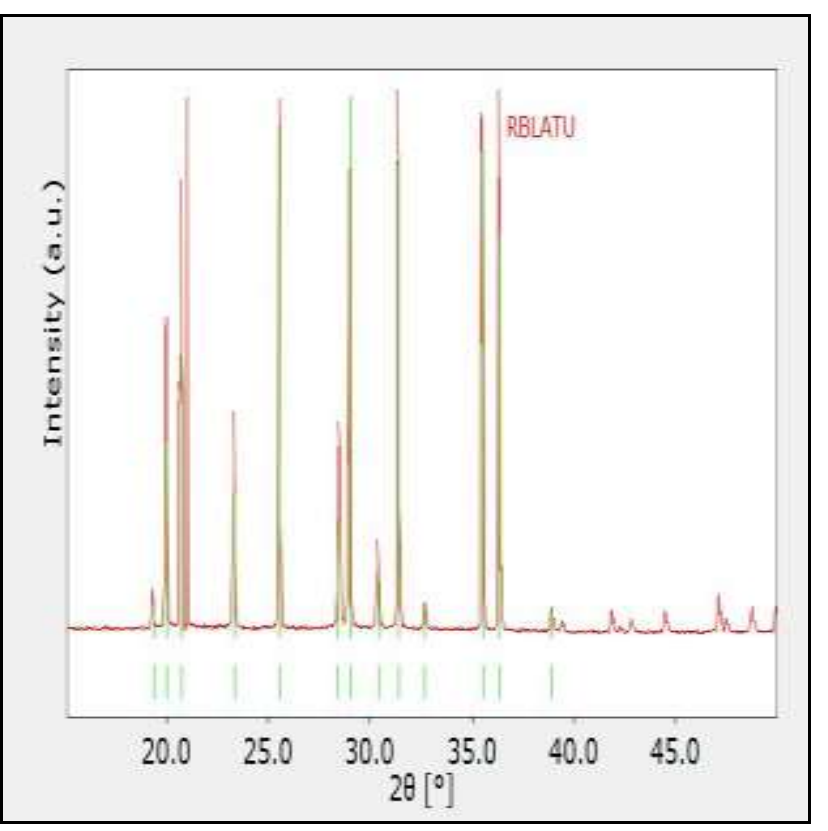

Figure 4. PWXRD spectrum of RBLATU crystal

\subsection{High resolution $X$-ray diffraction studies}

The crystalline perfection of the grown crystals were characterized by HRXRD analysis by employing a multicrystal X - ray diffractometer with $\mathrm{MoK} \alpha_{1}$ radiation designed and developed at National Physical Laboratory (NPL) New Delhi [15] has been used to record high-resolution diffraction curves (DCs). The well-collimated and monochromated MoKal beam obtained from the three monochromator Si crystals set in dispersive (+,-,-) configuration has been used as the exploring X-ray beam. The specimen crystal is aligned in the $(+,-,-,+)$ configuration. Due to dispersive configuration, though the lattice constant of the monochromator crystal(s) and the specimen are different, the unwanted dispersion broadening in the diffraction curve (DC) of the specimen crystal is insignificant. Before recording the diffraction curve, to remove the non-crystallized solute atoms remained on the surface of the crystal and also to ensure the surface planarity, the pure LATU and Rhodamine B dye admixtured LATU crystals were first lapped and chemically etched in a non-referential etchant of water and acetone mixture in 1:2 ratios. Figure 5 and Figure 6 show the highresolution diffraction curves (DCs) recorded for pure LATU and Rhodamine B dye admixtured LATU crystals using $\left(\begin{array}{llll}3 & 0 & 0\end{array}\right)$ diffracting planes in symmetrical Bragg geometry by employing the multicrystal X-ray diffractometer with $\mathrm{MoK} \alpha_{1}$ radiation.

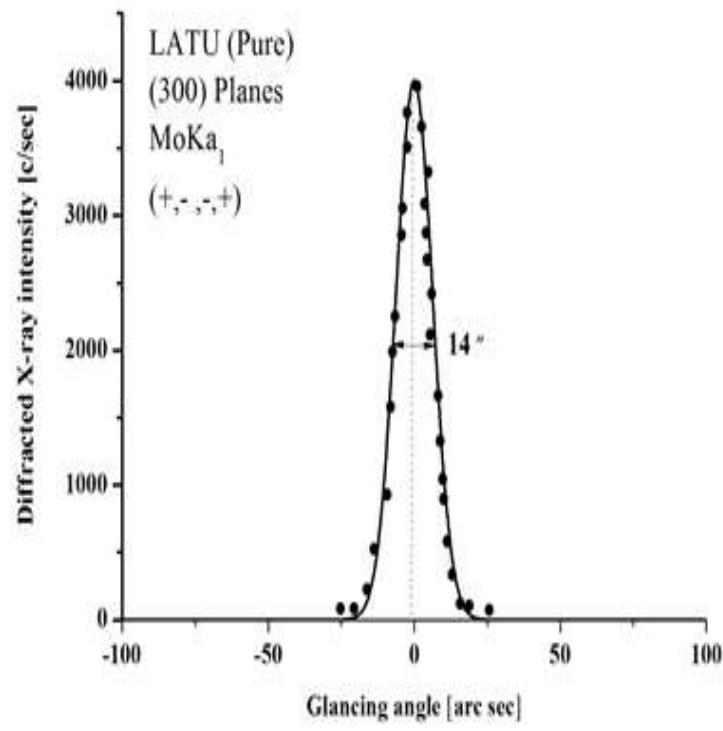

Figure 5. HRXRD curve of pure LATU crystal

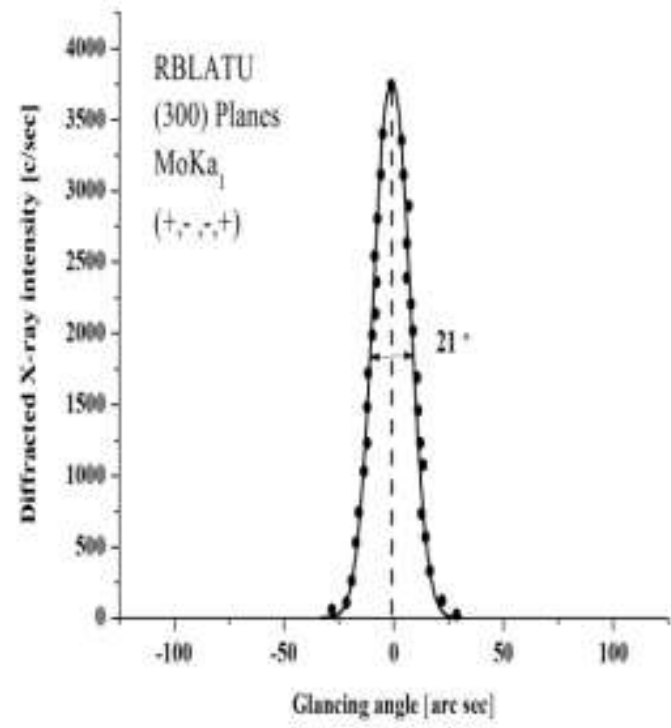

Figure 6. HRXRD curve of RBLATU crystal

The curves are very sharp having full width at half maximum (FWHM) of 14 arc sec for pure LATU and 21 arc sec for Rhodamine B dye admixtured LATU crystals as expected for nearly perfect crystals from the plane wave dynamical theory of X-ray diffraction [16]. The absence of additional peaks and the very sharp DC shows that the crystalline perfection of the specimen crystals is extremely good 
without having any internal structural grain boundaries and mosaic nature. The increase in FWHM without having any additional peaks in DC of Rhodamine B dye doped LATU crystal indicates the incorporation of Rhodamine B dye in the crystalline matrix of LATU crystal. In DC of Rhodamine B dye doped LATU crystal, for a particular angular deviation $(\Delta \theta)$ of glancing angle $(\theta)$ with respect to the Bragg peak position (taken as zero for the sake of convenience), the scattered intensity is much more in the positive direction in comparison to that of the negative direction. This feature or asymmetry in the scattered intensity clearly indicates that the Rhodamine B dopants predominantly occupy the interstitial positions in the lattice and elucidates the ability of accommodation of dopants in the crystalline matrix of the LATU crystal. This can be well understood by the fact that due to incorporation of dopants in the interstitial positions, the lattice around the dopants compresses and the lattice parameter d (interplanar spacing) decreases and leads to give more scattered (also known as diffuse X-ray scattering) intensity at slightly higher Bragg angles $\left(\theta_{\mathrm{B}}\right)$ as $\mathrm{d}$ and $\sin \theta_{\mathrm{B}}$ are inversely proportional to each other in the Bragg equation $\left(2 \mathrm{~d} \sin \theta_{\mathrm{B}}=\mathrm{n} \lambda ; \mathrm{n}\right.$ and $\lambda$ being the order of reflection and wavelength respectively which are fixed). It may be mentioned here that the variation in lattice parameter is only confined very close to the defect core which gives only the scattered intensity close to the Bragg peak. Long range order could not be expected and hence change in the lattice parameter is also not expected [17]. The HRXRD results confirm an important finding that Rhodamine B dye entrapped in the LATU crystals, but the amount is limited to a critical value and above which the crystals have a tendency to develop structural grain boundaries [18].

\subsection{Fourier Transform Infrared Spectroscopy}

The mid Fourier transform infrared spectrum of pure and dye doped LATU crystals were recorded at $300 \mathrm{~K}$ in the range of $4000-400 \mathrm{~cm}^{-1}$ using the $\mathrm{KBr}$ pellet technique. The FTIR spectra of pure and dye admixtured LATU crystals are shown in Figure 7 and Figure 8. The incorporation of Rhodamine B dye in LATU crystal has been strongly verified by spectral analysis. The O-H stretching due to water of crystallization arises at frequencies of 3788, 3558 and $3377 \mathrm{~cm}^{-1}$ in Rhodamine B dye doped LATU spectrum. The $\mathrm{NH}_{3}{ }^{+}$asymmetric bending and $\mathrm{CH}_{2}$ stretching vibrations occur at $3175 \mathrm{~cm}^{-1}$ and at $2815 \mathrm{~cm}^{-1}$. The asymmetric stretching vibration of $\mathrm{CO}_{2}$ is observed at $1558 \mathrm{~cm}^{-1}$. In the Rhodamine B dye LATU spectrum, the OH stretching in the high energy region is very much broadened, due to hydrogen bonding. The sharp peak at $2407 \mathrm{~cm}^{-1}$ is due to $\mathrm{NH}_{3}{ }^{+}$symmetric stretch out of plane vibration. The peak at $1362 \mathrm{~cm}^{-1}$ is due to $\mathrm{C}=\mathrm{S}$ stretching vibration. The aliphatic $\mathrm{C}-\mathrm{H}$ stretching mode at $2740 \mathrm{~cm}^{-1} \mathrm{confirms}$ the presence of Rhodamine B dye in LATU. The narrow bands at 679 and $581 \mathrm{~cm}^{-1}$ are observed in Rhodamine B dye added as compared to LATU. The vibration frequencies of L-Alanine Thiourea are compared with Rhodamine B dye admixtured L-Alanine Thiourea in Table 4 to confirm the incorporation of Rhodamine B dye in LATU crystal.

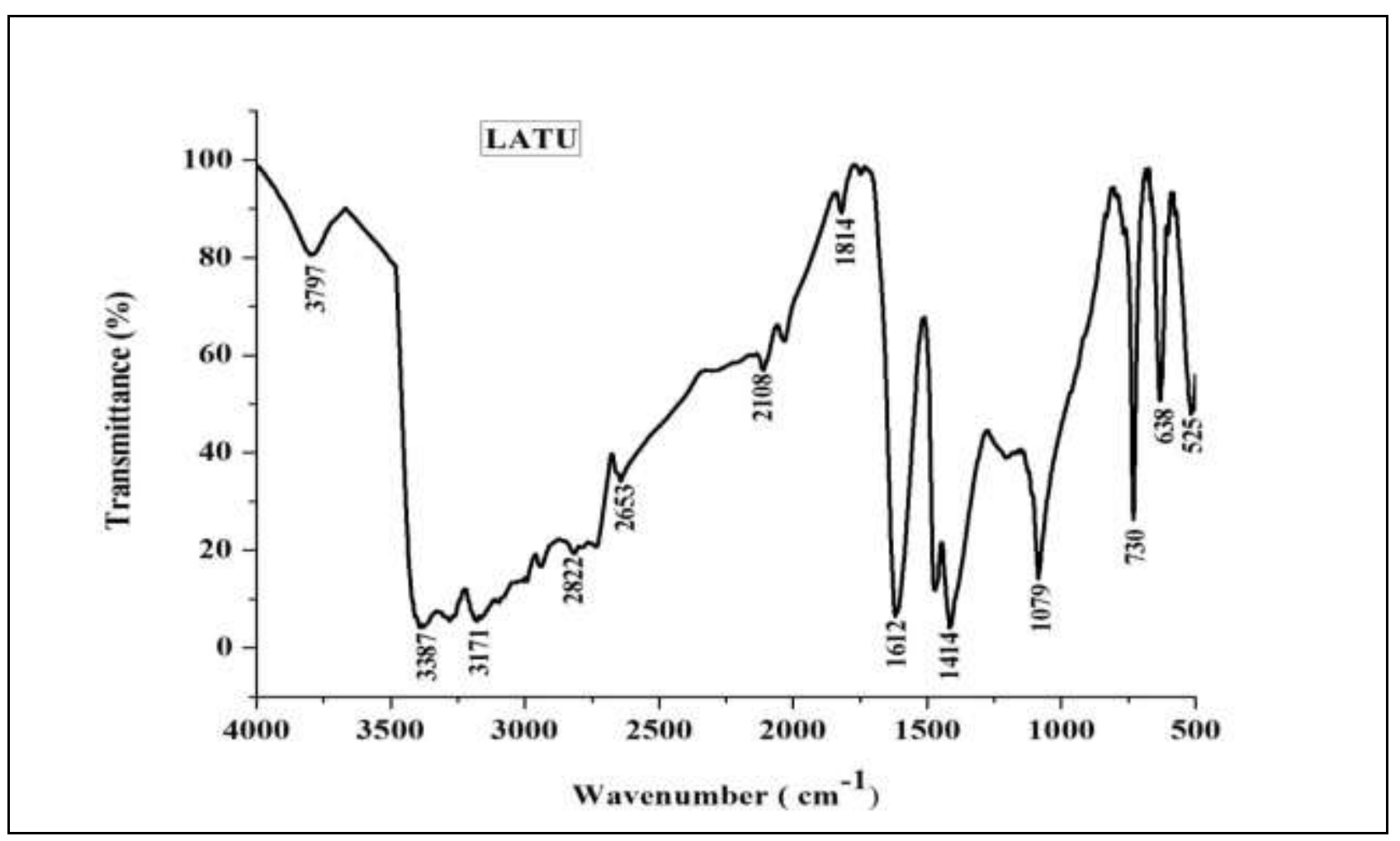

Figure 7. FTIR spectrum of grown L-Alanine Thiourea (LATU) single crystal. 


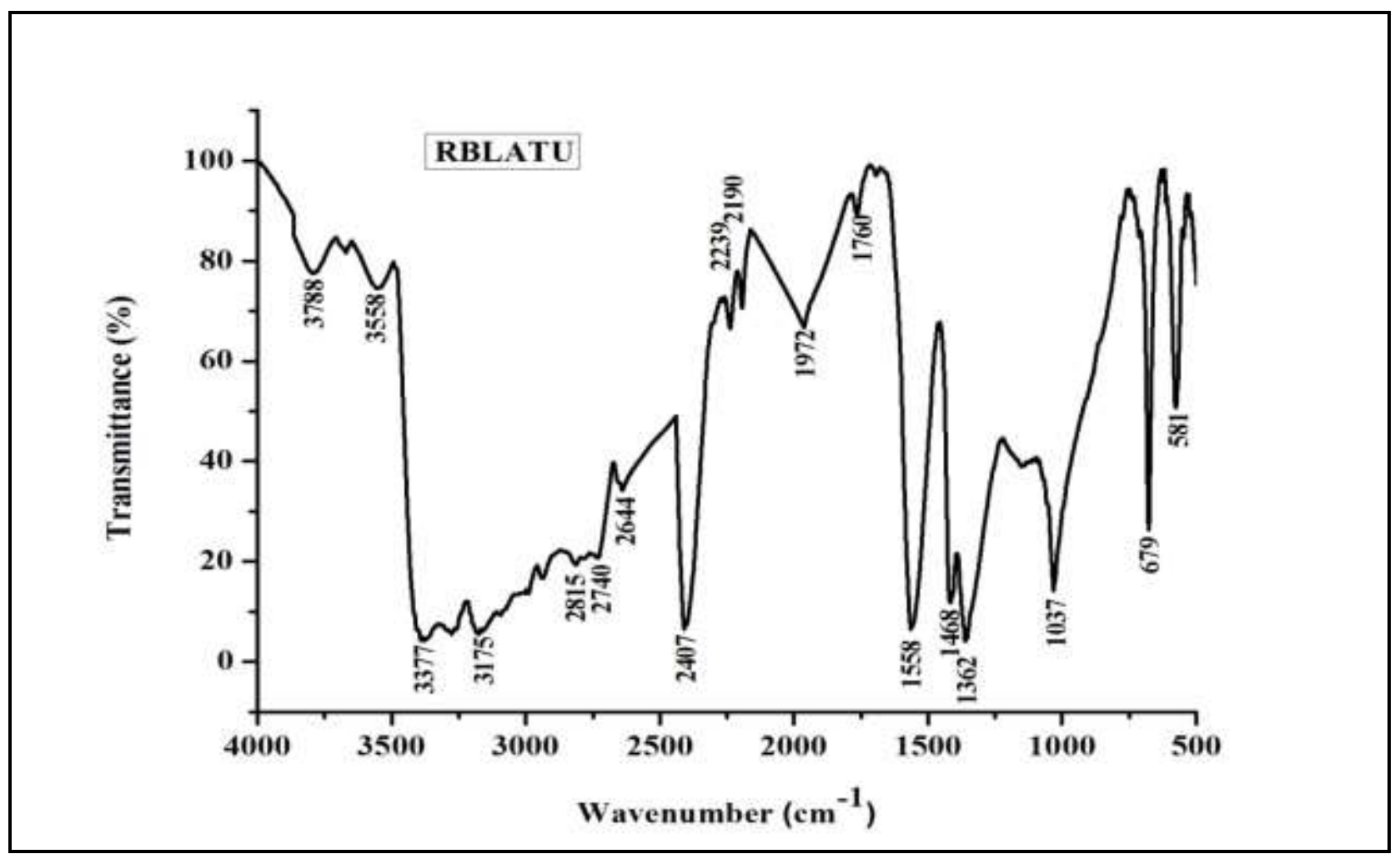

Figure 8. FTIR spectrum of grown Rhodamine B dye admixtured LATU (RBLATU) single crystal.

Table 4. Infrared absorption frequencies $\left(\mathrm{cm}^{-1}\right)$ of L-Alanine Thiourea (LATU) and Rhodamine B dye LATU (RBLATU) single crystals

\begin{tabular}{|c|c|c|l|}
\hline S.No. & $\begin{array}{c}\text { L-Alanine Thiourea } \\
\text { (LATU) }\end{array}$ & $\begin{array}{c}\text { Rhodamine B dye } \\
\text { admixtured LATU } \\
\text { (RBLATU) }\end{array}$ & \multicolumn{1}{|c|}{ Assignment } \\
\hline 1 & 3797 & 3788 & $\mathrm{OH}$ - stretching \\
\hline 2 & 3171 & 3175 & $\mathrm{NH}_{3}{ }^{+}$symmetric stretching \\
\hline 3 & 2822 & 2815 & $=\mathrm{CH}_{2}$ stretching \\
\hline 4 & - & 2740 & Aliphatic (C-H) stretch \\
\hline 5 & 2653 & 2644 & $\mathrm{C}-\mathrm{H}_{\text {symmetric stretching }}$ \\
\hline 6 & - & 2407 & $\mathrm{NH}_{3}{ }^{+}$symmetric stretch out of plane vibrations \\
\hline 7 & 2108 & 2190 & $\begin{array}{l}\text { Over tone region with a combination of symmetric } \mathrm{NH}_{3}{ }^{+} \text {bending } \\
\text { and torsional vibrations }\end{array}$ \\
\hline 8 & 1814 & 1972 & $\mathrm{C}=\mathrm{O}$ absorption \\
\hline 9 & 1612 & 1760 & $\begin{array}{l}\text { Asymmetric bending of } \mathrm{NH}_{3}{ }^{+} \text {and } \mathrm{C}=\mathrm{N} \\
\text { stretching }\end{array}$ \\
\hline 10 & 1414 & 1468 & $\mathrm{C}=\mathrm{O}$ stretching \\
\hline 11 & 1079 & 1037 & Symmetrical C-O-C stretching \\
\hline 12 & 730 & 679 & $\mathrm{C}-\mathrm{H}$ in plane bending \\
\hline 13 & 638 & 581 & $\mathrm{C}=\mathrm{S}$ stretching \\
\hline
\end{tabular}

\subsection{UV-visible spectral study}

The UV-visible spectra of pure and Rhodamine B dye admixtured analyses have been carried out using Shimadzu UV-visible spectrophotometer in the wavelength range of 100-1100 $\mathrm{nm}$. Transmission spectra are very important for any NLO material because a nonlinear optical material can be of practical use only if it has wide transparency window [19]. The UV-vis spectra of LATU and RBLATU are shown in Figure 9. In the case of pure LATU, a sharp fall in percent transmittance is occurred at $209 \mathrm{~nm}$. For $\mathrm{RB}$ admixtured LATU, the fall in percent transmittance are occurred at $370 \mathrm{~nm}$ and $322 \mathrm{~nm}$. It is followed by another percent transmittance at $295 \mathrm{~nm}$. Such variation in percent transmittance is due to electronic excitation of RB dye. It confirms that the addition of RB in the LATU crystal influence the light transmittance of LATU. In the transmission spectrum of Rhodamine B admixtured LATU, the characteristic absorption of Rhodamine B dye are observed at 370, 322 and $295 \mathrm{~nm}$. 


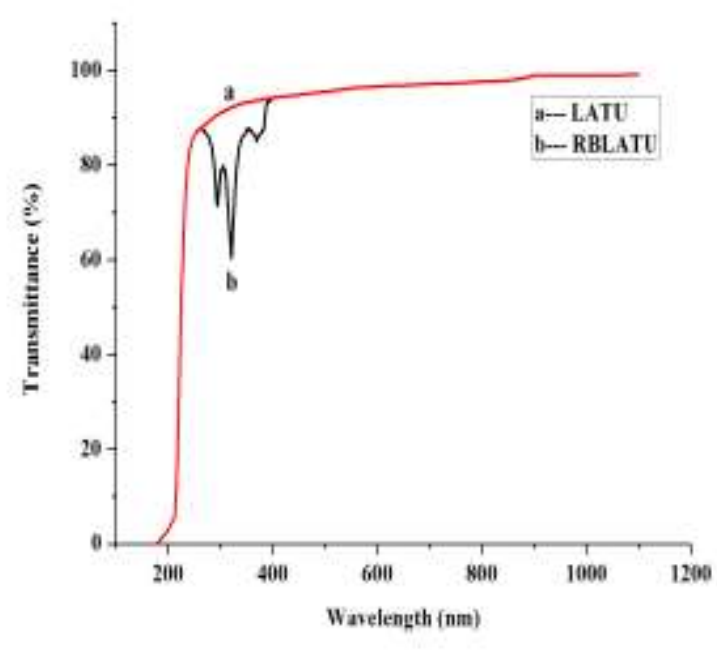

Figure 9. UV-vis-NIR absorption spectra for LATU and RBLATU crystals

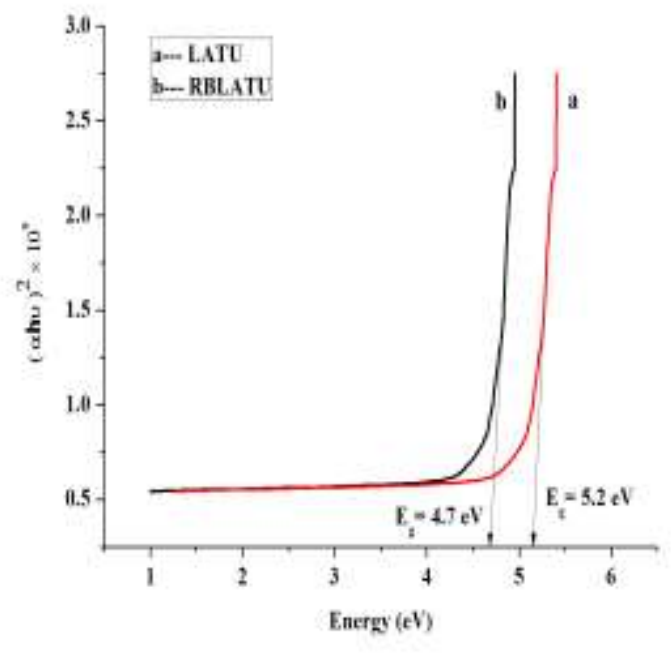

Figure 10. Photon energy vs $(\alpha h v)^{2}$ for LATU and RBLATU crystals

\subsection{Optical band gap energy $\left(\mathrm{E}_{\mathrm{g}}\right)$ calculation}

The band gap energy of the pure and Rhodamine B dye admixtured LATU crystals were calculated from the Figure 10 by taking Photon energy (hv) values along X-axis and $(\alpha h v)^{2}$ values along Y-axis for LATU and RBLATU crystals. The optical absorption coefficient $(\alpha)$ was calculated using the relation

$$
\alpha=(2.3026 * \log (1 / T)) / t
$$

where $\mathrm{T}$ is the transmittance and $\mathrm{t}$ is the thickness of the crystal. The band gap energy values were calculated by extrapolation of the linear part of the curve for LATU and RBLATU and found to be $5.2 \mathrm{eV}$ and $4.7 \mathrm{eV}$ respectively. The decrease in band gap energy value of dye admixtured LATU may be due to incorporation of dye in the LATU crystal lattices. The value of band gap energy for RBLATU crystal suggests that the material is dielectric in nature to possess wide transmission range. The large transmission in the entire visible region and lower cut off wavelength enable it to be a potential material for second and third harmonic generation [20].

\subsection{Thermo gravimetric analysis (TGA)}

Thermo Gravimetric Analysis (TGA) and Differential Thermal Analysis (DTA) were carried out for LATU and RBLATU crystals using TA Q-500 analyser. TGA and DTA curves for pure and Rhodamine B dye admixtured LATU are shown in Figure 11 and Figure 12.

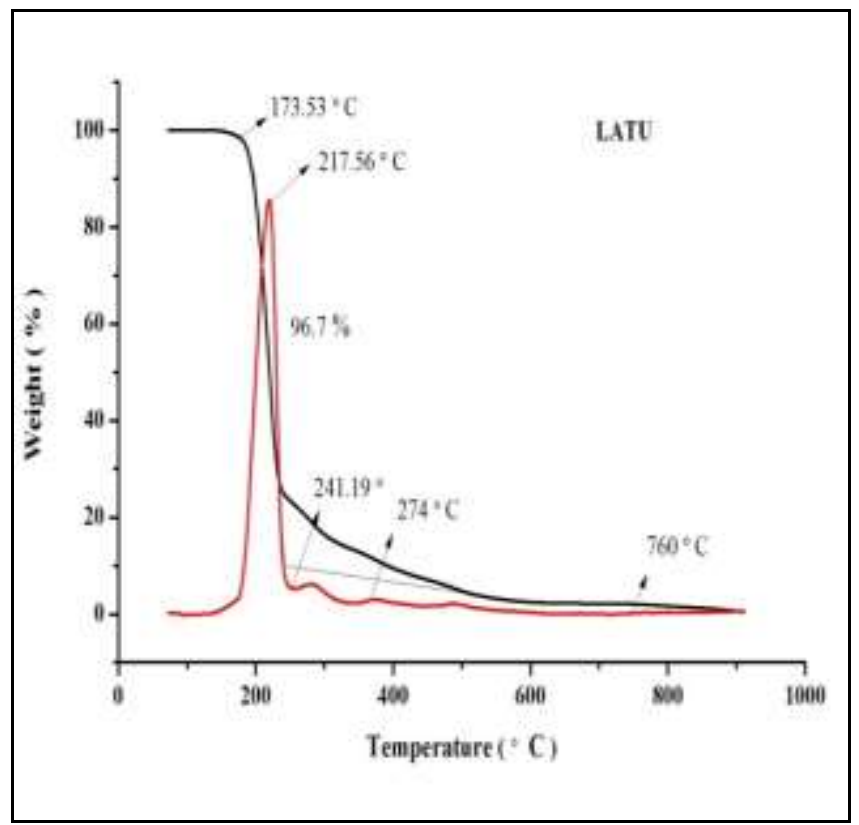

Figure 11. TGA and DTA curves of LATU crystal

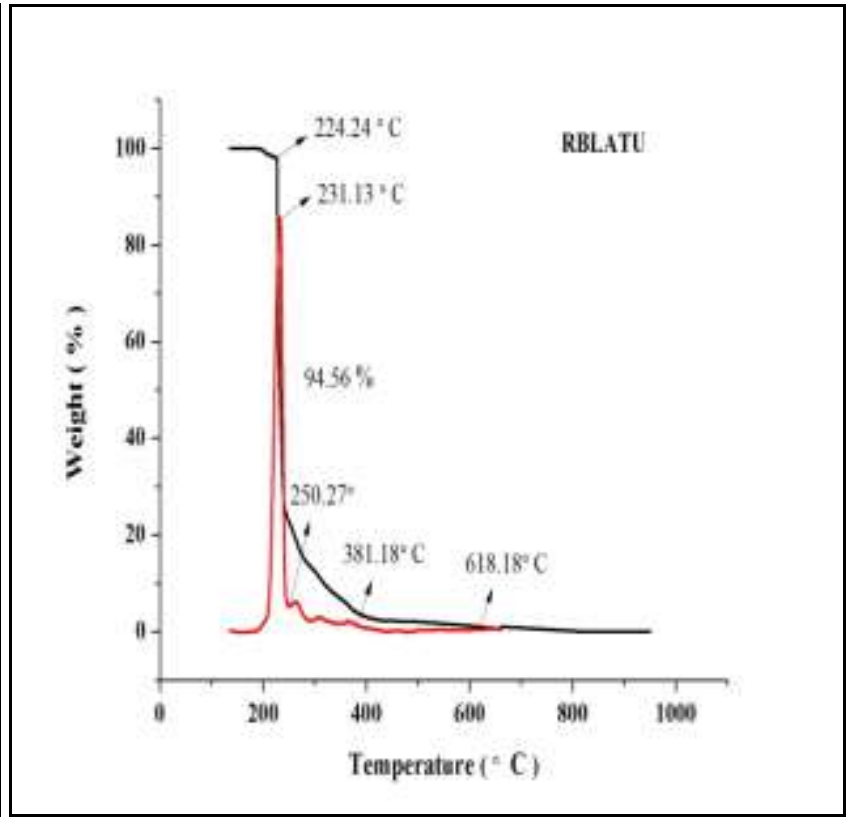

Figure 12. TGA and DTA curves of RBLATU crystal 
The powder samples were used for the analysis in the temperature range of $0{ }^{\circ} \mathrm{C}$ to $1000{ }^{\circ} \mathrm{C}$ at a heating rate of $10{ }^{\circ} \mathrm{C} / \mathrm{min}$ in the nitrogen atmosphere. In pure LATU, the major weight loss occurs between $173.53{ }^{\circ} \mathrm{C}$ and $241.19{ }^{\circ} \mathrm{C}$. The change in weight loss confirms the decomposition nature of the sample. Differential thermal analysis confirms through a sharp endothermic peak at $217.56{ }^{\circ} \mathrm{C}$ revealing the major weight loss. Further, degradation of the sample takes place from $274{ }^{\circ} \mathrm{C}$ to $760{ }^{\circ} \mathrm{C}$ where the loss of weight is about $5.41 \%$ due to liberation of volatile substances like sulfur oxide and amino acid L-Alanine [21]. The weight loss of $2.976 \%$ at the end is due to the release of $\mathrm{CO}$ molecules. Hence, it is concluded that the grown material is thermally stable up to $173.53{ }^{\circ} \mathrm{C}$. In Rhodamine B dye admixtured LATU crystal, the major weight loss occurs between $224.24{ }^{\circ} \mathrm{C}$ and $250.27{ }^{\circ} \mathrm{C}$. The change in weight loss confirms the decomposition nature of the sample. Differential thermal analysis confirms through a sharp endothermic peak at $231.13{ }^{\circ} \mathrm{C}$ revealing the major weight loss. Further, degradation of the sample takes place from $381.18{ }^{\circ} \mathrm{C}$ to $618.18{ }^{\circ} \mathrm{C}$ where the loss of weight is about $1.98 \%$ due to absorption of energy for breaking of bonds during the decomposition of the compound. Hence, it is concluded that the Rhodamine B dye admixtured LATU crystal is suitable for optoelectronics applications up to $224.24{ }^{\circ} \mathrm{C}$.

\subsection{Dielectric Analysis}

The dielectric studies of pure LATU and Rhodamine B dye admixtured LATU crystals were carried out using the HIOKI 3532-50 LCR HITESTER instrument. The capacitance values for LATU and RBLATU crystals were determined for frequencies varying from $50 \mathrm{~Hz}$ to $5 \mathrm{MHz}$ at room temperature. The variations of dielectric constant and dielectric loss as a function of log frequency are shown in Figure 13 and Figure 14. It is observed that the dielectric constant of pure LATU is 196 where 308 for Rhodamine B dye admixtured LATU crystal. The high value of dielectric constant at low frequencies may be due to incorporation of Rhodamine B dye in LATU in the grown crystal and better orientation of dipoles in the molecules of the crystals. The low value of dielectric loss indicates that the pure and Rhodamine B dye admixtured LATU crystals have lesser defects, which is a desirable property for NLO applications.

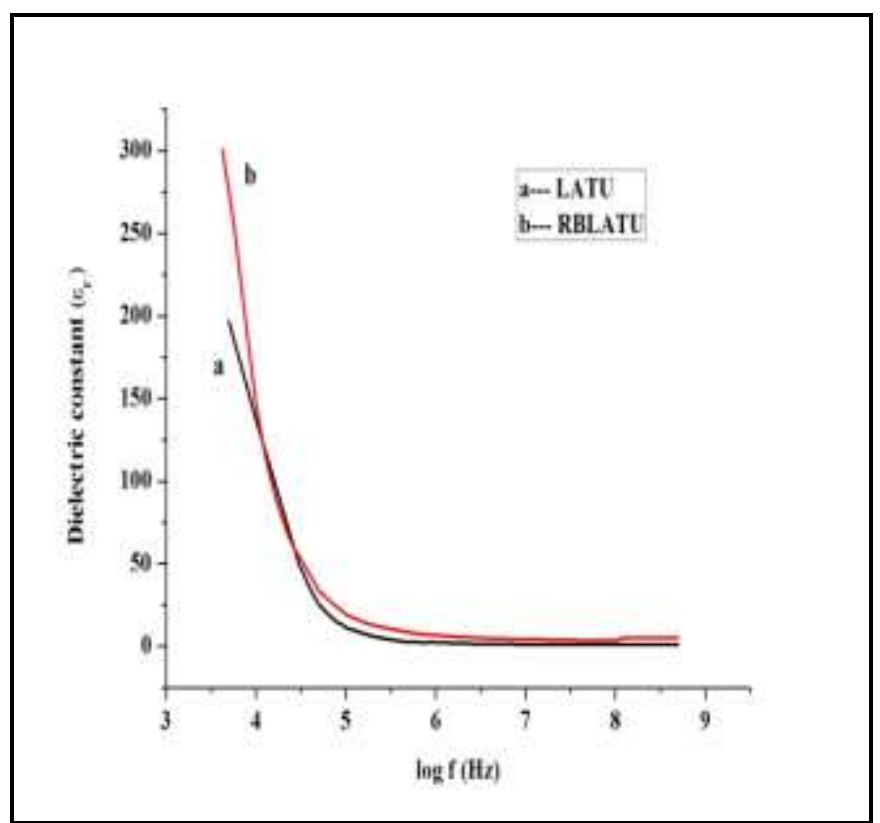

Figure 13. Variation of dielectric constant of pure LATU and RBLATU

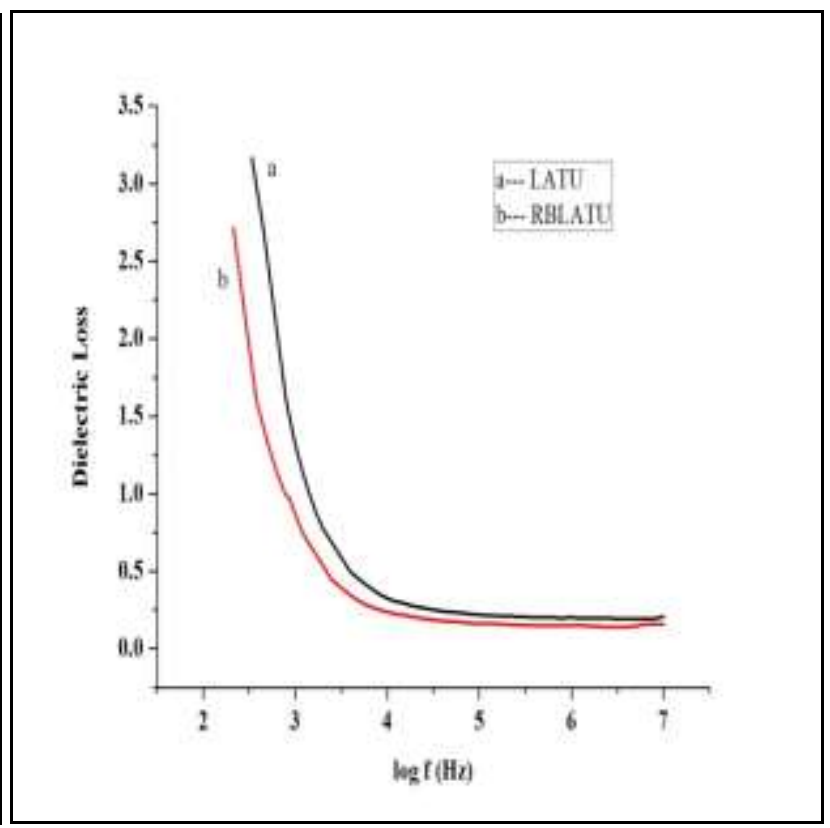

Figure 14. Variation of dielectric loss of pure LATU and RBLATU

\subsection{Microhardness Measurements}

Microhardness behaviour of pure LATU and RBLATU single crystals were tested by using Shimadzu make-model-HMV-2 fitted with Vickers pyramidal indenter and attached to an incident light microscope. The indentations were made on the flat surface with the load ranging from 25 to $100 \mathrm{~g}$ and the indentation time was kept as $10 \mathrm{~s}$ for all the loads. The Vickers hardness number $\mathrm{H}_{\mathrm{v}}$ was calculated from the following expression,

$$
\mathrm{H}_{\mathrm{V}}=((1.8544 * \mathrm{P})) / \mathrm{d}^{2} \quad \mathrm{~kg} / \mathrm{mm}^{2}
$$

where $\mathrm{P}$ is the applied load in $\mathrm{kg}, \mathrm{d}$ is the diagonal length of the indentation impression in mm and 1.8544 is a constant of a geometrical factor for the diamond pyramid. Vickers hardness number was calculated and a graph has been plotted between the hardness values and the corresponding loads for the crystals as shown in Figure 15. From the results, it is observed that the hardness number decreases with increasing load up to $75 \mathrm{~g}$ and attains saturation for further increase in load. Beyond this load cracks were found both in pure LATU and RBLATU single crystals. From the Figure 15, it is observed that the microhardness value of dye admixtured crystal is slightly higher than that of the pure LATU and it is due to the presence of organic Rhodamine B dye molecule in the interstitial sites of pure LATU crystal. 


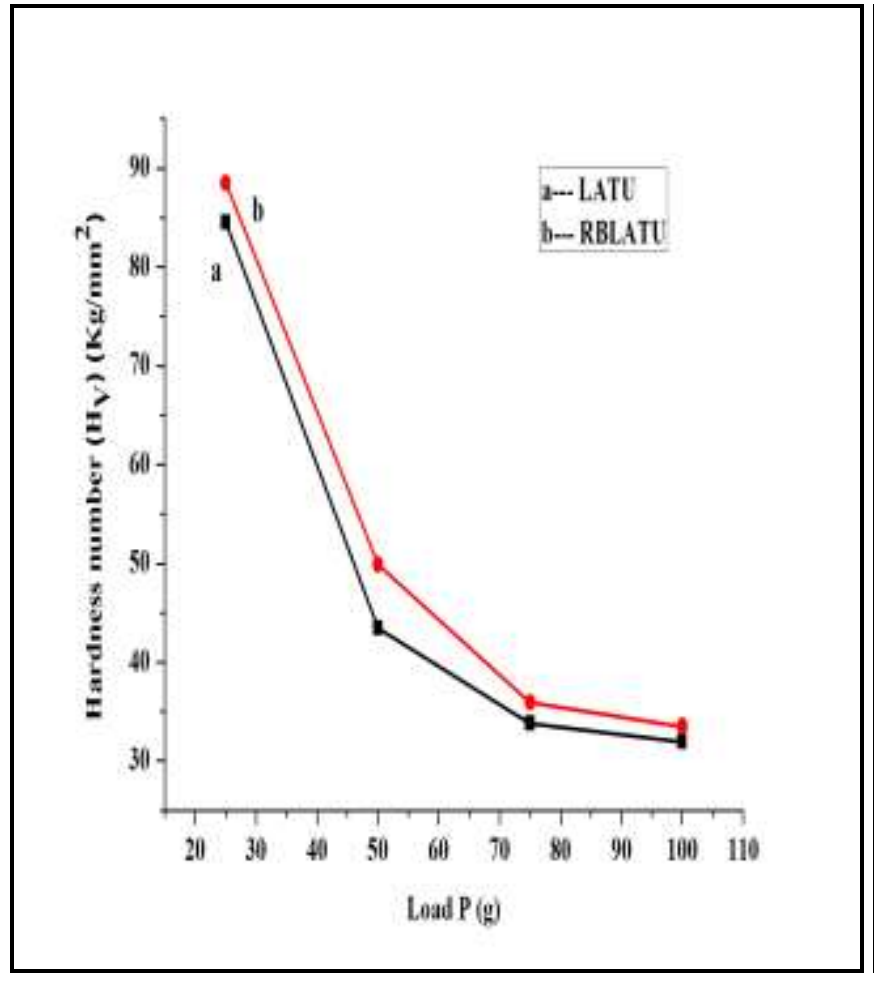

Figure 15. Variation of hardness with applied load for LATU and RBLATU single crystals

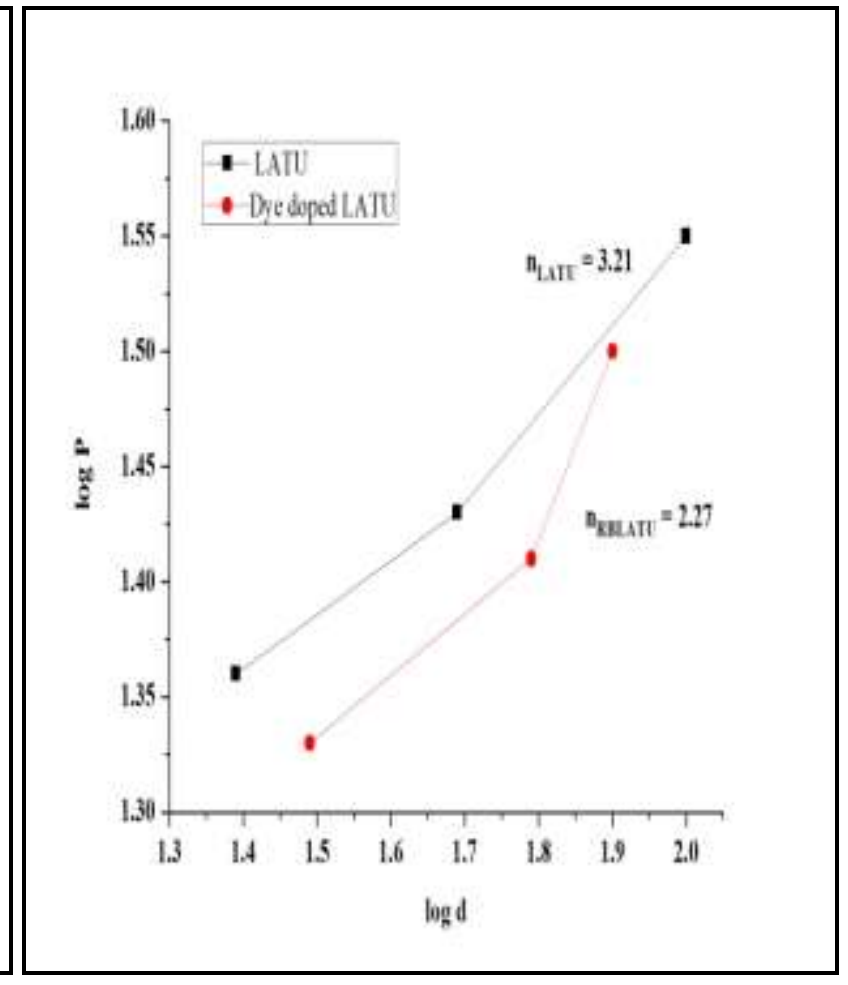

Figure 16. Variation of $\log (P)$ with $\log (d)$ for LATU and RBLATU single crystals

The Mayer's index number was calculated from the Mayer's law, which relates the applied load(P) and indentation diagonal length(d).

$$
\mathbf{P}=\mathbf{a d}^{\mathbf{n}}
$$

where ' $a$ ' is the material constant and ' $n$ ' is the Mayer's index or work hardening coefficient. The values of the work hardening coefficient (n) were estimated from the plot of $\log \mathrm{P}$ versus $\log \mathrm{d}$ drawn by the least square fit method and it is shown in Figure 16. The work hardening coefficients (n) for pure LATU and Rhodamine B dye admixtured LATU crystals were found to be 3.21 and 2.27 respectively. Onitsch [22] pointed out that ' $n$ ' lies between 1 and 1.6 for moderately hard materials and it is more than 1.6 for soft materials. The observed values of Mayer's index for LATU and RBLATU are 3.21 and 2.27 and hence they belong to the soft materials category.

\subsection{Laser damage threshold studies}

The laser damage density is one of the important parameters that decide the applicability of the material for high power laser applications. The laser damage threshold values were measured using a Q-switched Nd-YAG laser source of pulse width $10 \mathrm{~ns}$ and $10 \mathrm{~Hz}$ repetition rate operating in TEM00 mode. The energy per pulse of 532nm laser radiation attenuated using appropriate neutral density filters was measured using an energy meter (Coherent EPM 200) which is externally triggered by the Nd:YAG laser. If the material has a low damage threshold, it severely limits its application, though it may have excellent properties like high optical transmittance and high SHG efficiency [23]. For surface damage, the sample was placed at the focus of a plano-convex lens of focal length $30 \mathrm{~cm}$. The (100) plane of pure and dye admixtured crystals was used for the laser damage studies. The surface threshold of the crystal was calculated using the expression:

$$
\text { Power density }(\mathbf{P d})=\mathrm{E} / \tau \pi \mathbf{r}^{2}
$$

Where $E$ is the energy $(\mathrm{mJ}), \tau$ is the pulse width (ns) and $\mathrm{r}$ is the radius of the spot $(\mathrm{mm})$. The measured multiple shot (150 pulses) laser damage threshold values of pure and dye admixtured LATU crystals are 9 and $7.3 \mathrm{GW} / \mathrm{cm}^{2}$ respectively. The decrease in laser damage threshold value of dye admixtured LATU may be due to incorporation of dye in the LATU crystals

\subsection{NLO Studies}

Nonlinear optical (NLO) property of pure L-Alanine Thiourea (LATU) and Rhodamine B dye admixtured LATU crystals were determined by Kurtz powder technique using the Nd:YAG Q-switched laser beam. The samples of same sizes were illuminated using Q-switched, mode locked Nd:YAG laser with input pulse of $6.2 \mathrm{~mJ}$. The second harmonic signals of $384 \mathrm{mV}$ and $560 \mathrm{mV}$ were obtained for pure and Rhodamine B dye admixtured LATU crystals with reference to KDP (275 mV). Thus, the SHG efficiency of LATU and Rhodamine B dye admixtured LATU crystals was found to be 1.39 and 2.04 times greater than the standard KDP crystal. The relative SHG efficiency of Rhodamine B dye admixtured LATU crystal was found to be 1.46 times higher than that of pure LATU crystal. 


\section{CONCLUSION}

Good quality of LATU and Rhodamine B dye admixtured LATU crystals were grown by slow evaporation method. The unit cell parameters of the crystals obtained from single crystal XRD showed that the LATU and RBLATU crystals belong to monoclinic system with space group P2 ${ }_{1}$. Sharp peaks of powder XRD pattern of the crystals confirm the good crystalline nature of the grown crystals and the incorporation of Rhodamine B dye into LATU crystal lattice. The functional groups of RBLATU crystal were identified by FTIR spectral analysis and they have confirmed the presence of organic additive Rhodamine B dye in LATU crystal. The UV-vis-NIR transmittance spectra showed that the crystals had a wide optical window and the absorption due to Rhodamine B dye in LATU crystal. The addition of Rhodamine B dye in LATU crystal increased the thermal stability of pure LATU crystal. The sharpness of the endothermic peak shows good degree of crystallinity of the crystal. The Vickers micro hardness values were calculated in order to understand the mechanical stability of the crystals. Dielectric studies for the crystal were studied. NLO studies have confirmed that the SHG efficiency value was significantly enhanced due to the presence of Rhodamine B dye in LATU crystal.

\section{ACKNOWLEDGMENTS}

The authors thank Dr. G. Bhagavannarayana, NPL, New Delhi, for HRXRD studies. The authors express thanks to SAIF, IIT Madras Chennai for providing the spectral analysis.

\section{REFERENCES}

[1] J.F. Nicoud, R.J. Twieg, "Nonlinear Optical Properties of Organic Molecules and Crystals", Eds. D.S. Chemla and J. Zyss, Academic Press, London, pp 227-296(1987).

[2] M. Delfino, “Mol. Cryst. Liq. Cryst.”, 52, 271(1979).

[3] J.D. Bernal, Z. Kristallogr. 78, 363(1931).

[4] H.J. Simpson Jr., R.E. MARSH, Acta Cryst. 8, 550(1966).

[5] R. Destro, R.E. Marsh, R. Bianchi, Journal of Physical Chemistry, 92, 966(1988).

[6] M. Bowman, S. K. Debray, and L. L. Peterson, "Reasoning about naming systems. ACM Trans. Program. Lang. Syst.", 15(5):795-825(1993).

[7] P. Angeli Mary, S. Dhanuskodi, Cryst. Res. Technol., 36, 1231 (2001).

[8] H.K. Hellwege, A.M. Hellwege, "Landolt-Bornstein: Numerical Data and Functional Relationship in Science and Technology Group II”, Springer, Berlin, pp. 584-586(1982).

[9] S. Alfred Cecil Raj, "Growth, Spectral, Optical and Thermal characterization of NLO Organic Crystal - Glycine Thiourea", International Journal of Chem Tech Research, vol.5, pp. 482-490(2013).

[10] S. Nalini Jayanthi, A. R. Prabhakaran, D. Subashini, "Growth and characterization of a Non-Linear Optical crystal: Thiourea added L-Histidine crystals", International Journal of Advances in Engineering \& Technology, ISSN: 2231-1963(2013).

[11] Yu., Velikhov, “Growth and properties of dyed KDP crystals” Cryst. Res. Technol., vol. 42, pp. 27-33(2007).

[12] J.B. Benedict, P.M. Wallace, P.J. Reid, S.H. Jang, B. Kahr, Advanced Materials, vol. 15, pp. 1068-1070(2003).

[13] I. Vogel, A Text Book of Quantitative Inorganic Analysis, 3rd edn ( London, Logman Green \& Co. Ltd. ), 428(1961).

[14] S. Palanisamy, O. N. Balasundaram, "Growth, Optical and Mechanical Properties of Alanine Sodium Nitrate (ASN)", Rasayan Journal of Chemistry, vol. 1, pp. 782-787(2008).

[15] K. Lal, G. Bhagavannarayana, "A high-resolution diffuse X-ray scattering study of defects in dislocation free silicon crystals grown by the float-zone method and comparison with Czochralski-grown crystals", J. Appl. Cryst., vol. 22, pp. 209-215(1989).

[16] B.W. Batterman, H. Cole, "Dynamic diffraction of X-rays by perfect crystals”, Rev. Mod. Phys., vol. 36, pp. 681-717(1964).

[17] G. Bhagavannarayana, S.K. Kushwaha, M. Shakir, K.K. Maurya, J. Appl. Crystallogr., vol. 44, pp. 122-128(2010).

[18] G. Bhagavannarayana, S.K Kushwaha, "Enhancement of SHG efficiency by urea doping in ZTS single crystals and its correlation with crystalline perfection as revealed by Kurtz powder and high-resolution X-ray diffraction methods", J. Appl. Crystallogr., vol. 43, pp. 154-162(2010).

[19] P. Anandan, R. Jayavel, T. Saravanan, G. Parthipan, C. Vedhi, R. Mohan Kumar, "Crystal growth and characterization of L-histidine hydrochloride monohydrate semiorganic nonlinear optical single crystals", Optical Materials, vol. 30, pp. 12251230(2012).

[20] J. Ramajothi, S. Dhanuskodi, "Crystal growth, thermal and optical studies on a semiorganic nonlinear optical material for bluegreen laser generation", Spectrochimica Acta part A, vol. 68, pp. 1213-1219,(2007).

[21] N.R. Dhumane, S.S. Hussaini, Kunal datta, Prasanta ghosh and D. Mahendra, Shirsat, J. Pure Appl. \& Ind. Phys., vol. 1, pp. 4552,(2010).

[22] E.M. Onitsch, "The present status of testing the hardness of materials”, Mikroskopie. vol. 95, pp. 12-14,(1956).

[23] D. Kalaiselvi, R. Mohan Kumar, R. Jayavel, "Growth and Characterization of nonlinear optical L-arginine maleate dehydrate single crystals”, Materials Letters, 61, 755-758,(2008). 